\title{
Üst Ekstremite Periferik Arter Yaralanmalarında Ultrason Eşliğinde Supraklavikuler Blok; Hızlı, Kolay ve Güvenilir Bir Anestezi Yaklaşımı
}

\section{Ultrasound Guided Supraclavicular Block for Upper Extremity Peripheral Artery Lacerations; a Fast, Easy and Safe Anaesthetic Management}

\author{
Mustafa Özgür ${ }^{1}$, Ali İhsan Hasde ${ }^{1}$, Ayhan Köseoğlu ${ }^{1}$
} ${ }^{1}$ Antakya Devlet Hastanesi
Antakya- Türkiye

Corresponding Author:

Dr. Mustafa Özgür

\section{Address:}

Antakya Devlet Hastanesi, Antakya

Tel: 03262194000

\section{E-mail:}

mustafazgr75@gmail.com

\section{Başvuru Tarihi/Received :}

11-01-2014

\section{Kabul Tarihi/Accepted:}

06-08-2014

\section{ÖZET}

Amaç: Periferik damar yaralanmaları yüksek mortalite ve morbidite nedeniyle acil müdahale gerektiren önemli bir durumdur. Biz de bu nedenle acil olarak opere edilen üst ekstremite periferik arter kesilerinde 14 olguda ultrason rehberliğinde yaptığımız supraklavikular blok deneyimlerimizi literatür eşliğinde paylaşmayı amaçladık.

Yöntem: 2013 yllında Antakya devlet hastanesi kalp damar cerrahisi kliniği tarafından üst ekstremite periferik arter kesisi nedeniyle opere edilen ASA I-II, 17-41 yaş aralığında 14 hasta değerlendirildi. Hastalara supin pozisyonda ultrason eşliğinde supraklavikuler brakiyal pleksus bloğu uygulandı. Hastaların yaş, cinsiyet, boy, kilo ve ASA skorları, travmanın yeri ve ek travma bulguları blok oluşma zamanı ve blok uygulama süreleri kaydedildi.

Bulgular: Olguların erkek/kadın oranı 10/4 olarak bulunmuştur. Üst ekstremite yaralanma dağılımları incelendiğinde en s1k oranda (\%50) radial arter kesisi görülmüştür. Blok uygulama süresi ve blok oluşma zamanı olarak olgularda anlamlı fark saptanmamıştır. Blok uygulama süresi ortalama $8,45 \mathrm{dk}$. blok oluşma zamanı ise ortalama $10,7 \mathrm{dk}$. olarak bulunmuştur.

Sonuç: Tüm olgularda ultrason eşliğinde supraklavikuler brakiyal pleksus bloğu başarıyla uygulanmıştır. Supraklavikuler blokta en ciddi komplikasyon pnömotoraks ve vasküler travma oluşmasıdır. Olgularımızın hiçbirinde intraoperatif ve erken postoperatif dönemde komplikasyon görülmemiştir. Ultrason eşliğinde uygulanan supraklavikuler brakiyal pleksus bloğu üst ekstremite periferik arter kesilerinde de kolay uygulanabilen güvenli bir anestezi yönetimi sağlamıştır.

\section{Anahtar Kelimeler: Ultrason, sinir bloğu, kardiyovasküler}

\section{ABSTRACT}

Objective: Peripheral artery injures are important conditions which require an emergency response due to high mortality and morbidity. We, therefore, aimed our ultrasound guided supraclavicular block research on 14 patients, who each received emergency surgery for upper extremity peripheral artery lacerations; in conjunction with the literature.

Methods: This study consisted of 14 patients, aged between 17-41 years old, who underwent surgery for upper extremity peripheral artery lacerations at the Antakya State Hospital Cardiovascular Surgery Clinic in 2013 (ASA I-II scores). Ultrasound guided supraclavicular brachial plexus blocks were administered to the patients in the supine position. The patients' age, sex, height, weight, ASA scores, the localization of the trauma and additional trauma results, block formation time and block administration period were recorded.

Results: The male/female ratio of the cases was 10/4, and radial artery lacerations $(50 \%)$ were seen most frequently. There was no significant difference between the cases in terms of block formation time and block administration period. The mean block administration period was determined to be $8,45 \mathrm{~min}$, and the mean block formation time was 10,7 min.

Conclusion: The most severe complications for supraclavicular blocks are pneumothorax and vascular trauma. There were no complications in any of our cases in the intraoperative or early postoperative period. Consequently, we believe that ultrasound guided brachial plexus blocks can also be administered quickly and safely for peripheral artery lacerations.

Key Words: Ultrasound, nerve block, cardiovascular 
DOI: $10.16899 /$ ctd.57811

\section{GíRiş}

Periferik damar yaralanmaları yüksek mortalite ve morbidite nedeniyle acil müdahale gerektiren önemli bir durumdur. Tüm travmaların \%1-3'ünü vasküler travmalar oluşturmaktadır (1). Hastaların sağlık merkezine ulaşması ve yapılan müdahale arasındaki süre morbidite ve mortaliteyi etkileyen önemli etkenlerden biridir (2). Acil olarak başvuran hastalarda cerrahi müdahale kan kaybını önlemek ve hemodinamiyi düzeltmek için zaman kaybetmeden uygulanmalıdır. $\mathrm{Bu}$ hastalarda anestezi yönetimi de en az cerrahi yaklaşım kadar hızlı, kolay uygulanabilir ve etkin olmalıdır. $\mathrm{Bu}$ nedenle acil olarak opere edilen üst ekstremite periferik arter kesilerinde 14 olguda ultrason (US) yardımıyla yaptığımız supraklavikuler blok deneyimlerimizi literatür eşliğinde paylaşmayı amaçladık.

\section{GEREÇ VE YÖNTEM}

2013 y1linda Antakya devlet hastanesi kalp damar cerrahisi kliniği tarafindan üst ekstremite periferik arter kesisi nedeniyle opere edilen ASA I-II, 17-41 yaş aralığında 14 hasta değerlendirildi. Hastaların yazılı onamları alınarak yapılacak işlem hakkında bilgilendirme yapıldı. Hastalar ameliyathaneye alındıktan sonra standart anestezi monitorizasyonu uygulandı (elektrokardiyografi, pulsoksimetre, non invaziv kan basıncı). Tüm hastalara opere olmayacak koldan $18 \mathrm{G}$ kanül ile damar yolu açıldı. Genel anestezi şartları sağlandıktan ve damar yolu açıldıktan sonra cilt antisepsisini takiben hastalara supin pozisyonda US eşliğinde supraklavikuler brakiyal pleksus bloğu uygulandı. Blok için Sonosite M Turbo US cihazı (SonoSite ${ }^{\mathrm{TM}}$, Bothell, WA, USA) ve 6 $\mathrm{MHz}$ lineer prob kullanıldı. Klavikula üzerinde prob koronal oblik planda tutularak subklavyen arter ve brakiyal pleksus gözlemlendi (Resim 12). İn plane teknikle $80 \mathrm{~mm}$ Stimuplex D plus iğnesi (B. Braun, Melsungen AG, Germany) kullanılarak lokal anestezik solusyonu $(20 \mathrm{ml}$. $\% 0,5$ bupivakain $+20 \mathrm{ml}$. $\% 2$ lidokain) tüm pleksusu çevreleyecek şekilde uygulandı. Hastaların yaş, cinsiyet, boy, kilo ve ASA skorlar1, travmanın yeri ve ek travma bulguları blok oluşma zamanı ve blok uygulama süreleri kaydedildi. Blok oluşma zamanı brakiyal pleksusa ilaç verildikten cerrahiye başlama zamanına kadar geçen süre olarak kaydedildi. Blok uygulama süresi ise iğnenin cildi geçtiği andan itibaren lokal anesteziğin verilip iğnenin geri çekilmesine kadar geçen süre olarak kaydedildi. Ayrica hastalar hem erken hem de geç dönemde oluşabilecek komplikasyonlar açısından takip edildi.

Resim 1: Supraklavikuler bölgenin ultrasonografik görüntüsü

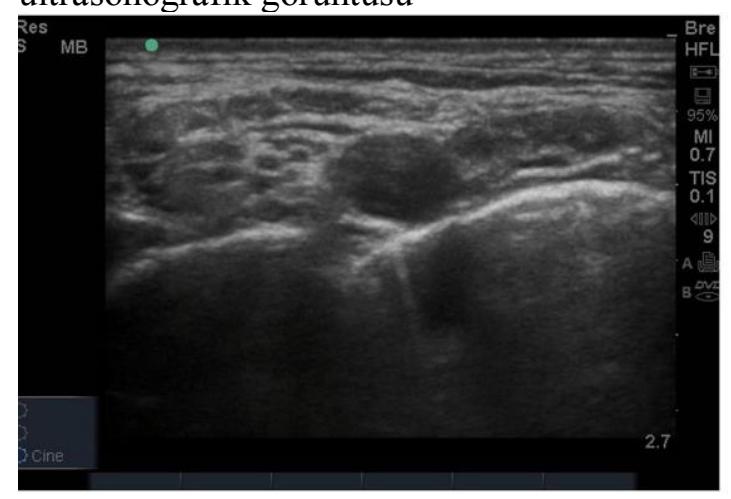

Resim 2: Sinir blokaj iğnesinin perivasküler alandaki görüntüsü

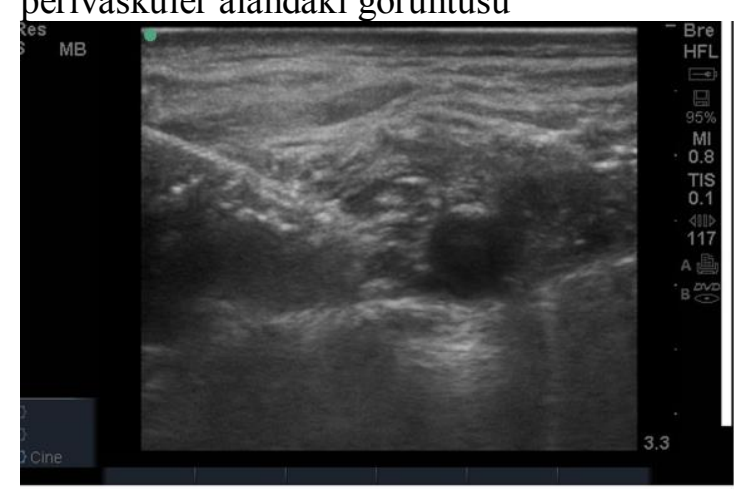


Grafik 1: Olguların yaralanma nedenleri. ASY: Ateşli silah yaralanması, KDAY: Kesici delici alet yaralanması, TK: Trafik kazası.

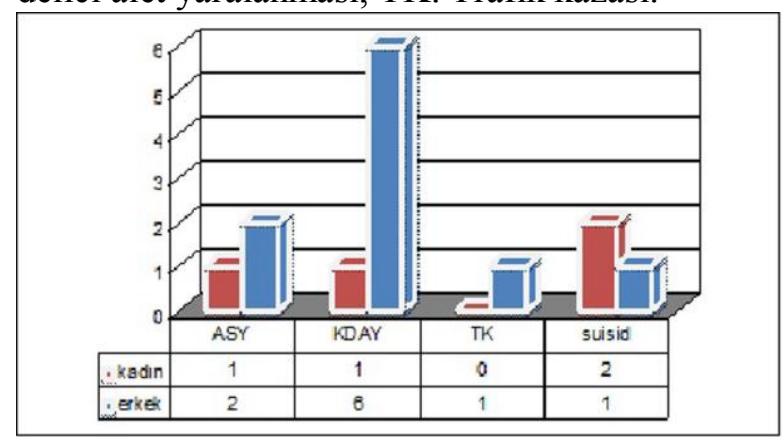

Verilerin istatiksel analizi SPSS 16.0 istatistik paket programında yapıld. Tanımlayıcı istatistikler sürekli değişkenler için ortalama \pm standart sapma veya medyan (minimummaksimum) olarak kategorik değişkenler ise olgu sayısı (n) ve yüzde (\%) şeklinde gösterildi.

\section{BULGULAR}

Hastaların üst ekstremite yaralanma dağılımları Tablo 1'de gösterilmiştir. Olguların erkek/kadın oranı 10/4 olarak bulunmuştur. Üst ekstremite yaralanma dağılımları incelendiğinde en sik oranda $(\% 50)$ radial arter kesisi görülmüştür. Hastaların demografik özellikleri, blok oluşma ve uygulama süreleri Tablo 2' de gösterilmiştir. Blok uygulama süresi olarak hastalar arasında anlamlı fark saptanmamıştır. Blok uygulama süresi erkek hastalarda ortalama $7,81 \mathrm{dk}$. ve kadın hastalarda $10,08 \mathrm{dk}$. olarak bulunmuştur. Blok oluşma zamanı erkek hastalarda 10,1 dk. ve kadın hastalarda 12,3 dk. olarak bulunmuştur. Olguların yaralanma nedenleri Tablo 3'de gösterilmiştir. Yaralanma nedeni olarak kadınlarda 2 hastada suisid amaçlı olarak kendine zarar verme yoluyla damar yaralanması ve erkeklerde 6 hastada kesici delici alet yaralanmas1 en sik görülmüştür. Tüm hastalara aynı anestezist tarafindan ultrason rehberliğinde supraklavikuler brakiyal pleksus bloğu başarıyla uygulanmıştır. Olgulardan 2 hastaya ek sedasyon uygulanmış, yalnızca 1 hastaya ek analjezik yapılmıştır.
Tablo 1: Olguların üst ekstremitedeki yaralanma dağ 1 lımı

\begin{tabular}{|l|l|l|}
\hline & $\begin{array}{l}\text { Kadın } \\
(\mathbf{n = 4})(\%)\end{array}$ & $\begin{array}{l}\text { Erkek } \\
(\mathbf{n = 1 0})(\%)\end{array}$ \\
\hline Brakial arter & - & $1(10)$ \\
\hline Radial arter & $2(50)$ & $5(50)$ \\
\hline Ulnar arter & $1(25)$ & $3(30)$ \\
\hline Radial + ulnar arter & $1(25)$ & $1(10)$ \\
\hline
\end{tabular}

Tablo 2: Olguların demografik özellikleri, blok oluşma zamanları ve blok uygulama süreleri.

\begin{tabular}{|c|c|c|c|c|c|}
\hline & $\begin{array}{c}\text { Yaş } \\
\text { (Yıl) } \\
\text { Median } \\
\text { (Min- } \\
\text { Maks) }\end{array}$ & $\begin{array}{c}\text { Kilo } \\
\text { (kg) } \\
\text { Media } \\
\text { n } \\
\text { (Min- } \\
\text { Maks) }\end{array}$ & $\begin{array}{c}\begin{array}{c}\text { Boy } \\
\text { (cm) }\end{array} \\
\text { Media } \\
\text { n } \\
\text { (Min- } \\
\text { Maks) }\end{array}$ & $\begin{array}{c}\text { Blok } \\
\text { oluşm } \\
\text { a } \\
\text { zama } \\
\text { nı } \\
\text { (dk.) } \\
\text { (Ort } \pm \\
\text { SS) } \\
\end{array}$ & $\begin{array}{c}\text { Blok } \\
\text { uygulam } \\
\text { a süresi } \\
\text { (dk.) } \\
\text { (Ort } \pm \\
\text { SS) }\end{array}$ \\
\hline $\begin{array}{l}\text { Erkek } \\
(n=10)\end{array}$ & $\begin{array}{c}23,3 \\
(18,00- \\
29,00)\end{array}$ & $\begin{array}{c}77,50 \\
(58,00 \\
- \\
95.00) \\
\end{array}$ & $\begin{array}{c}171,5 \\
(160- \\
185)\end{array}$ & $\begin{array}{c}10,1 \pm \\
4\end{array}$ & $\begin{array}{c}7,81 \pm 5,1 \\
2\end{array}$ \\
\hline $\begin{array}{c}\text { Kadın } \\
(n=4)\end{array}$ & $\begin{array}{c}25,5 \\
(17,00- \\
31,00)\end{array}$ & $\begin{array}{l}61,00 \\
(48,00 \\
- \\
75,00) \\
\end{array}$ & $\begin{array}{c}159,2 \\
5 \\
(155- \\
168) \\
\end{array}$ & $\begin{array}{c}12,3 \pm \\
5\end{array}$ & $\begin{array}{c}10,08 \pm 6 \\
11\end{array}$ \\
\hline P değeri & 0,785 & 0,258 & 0,564 & 0,234 & 0,115 \\
\hline
\end{tabular}

Ort: Ortalama, SS: Standart sapma

\section{TARTIŞMA}

Rejyonal anestezi uygulamalarında hastanın bilincinin açık olması, şikayetlerini söyleyebilmesi, spontan solunumunun devam etmesi, havayolu reflekslerinin korunmas1, postoperatif dönemde analjezinin devam etmesi ve hastanin erken mobilizasyonu gibi önemli avantajlar vardır (3). Bunun yanında son 10 yılda rejyonal anestezide US'un kullanımının artmasıyla özellikle üst ekstremitede brakiyal pleksus blokları sıklıkla US eşliğinde uygulanmaya başlanmıştır. Üst ekstremitede brakiyal pleksusa ulaşım yerlerinden biri olan supraklavikular bölge özellikle yüzeyel yakınlığı ve subklavian arter ile anatomik komşuluğu 
DOI: $10.16899 /$ ctd. 57811

nedeniyle US'da rahatlıkla görülebilmektedir. $\mathrm{Bu}$ da bloğun başarı oranını artırmasının yanında kolay ve yaygin kullanılmasina olanak sağlamıştır (4). Yapılan bir çalışmada Chan ve ark. supraklavikular blok uyguladıkları hastalarda başarı oranını \%95 olarak belirtmişlerdir (5). Deneyimli olabilmek için Sandhu ve ark. US eşliğinde en az 20 blok yapılmasını önermişlerdir (6). Bizim çalışmamızda deneyimli bir el ile bu oran benzer bir şekilde \%93 olarak yüksek bulunmuştur. Perlas ve ark ise 510 hastanın 12 sinde $(\% 2,6)$ başarısız blok belirtmişlerdir (7). Bizim çalışmamızda ise sadece 1 hastada blok sonrası operasyon esnasında ek analjezik ihtiyacı olmuştur.

US eşliğinde yapılan supraklavikular bloğun en büyük avantajı brakiyal pleksusa rahat ulaşmanın yanında plevra, subklavian arter ve ven gibi çevre dokuların görülebilmesidir ve intravasküler enjeksiyon ve pnömotoraks gibi komplikasyonların önlenmesidir. Ancak tüm avantajlarına rağmen intravasküler enjeksiyon gibi komplikasyonların US ile de oluşabileceğini gösteren yayınlar vardır $(8,9)$.

Yapılan bir çalışmada US eşliğinde yapılan supraklavikular brakiyal pleksus bloğunun nörostimulatör tekniğe oranla özellikle ulnar arterde sempatik blok derecesini ve kan akımını artırdığı tespit edilmiştir (10). Bu açıdan bakıldığında özellikle el cerrahisinde arter anastomozlarında kan akımının artması cerrahi açıdan yararlı bir durum oluşturmaktadır. Fakat kan akımının arttığını destekleyecek daha fazla çalışmanın gerekli olduğunu düşünüyoruz.

Brakiyal pleksusun supraklavikular bölgede 1. kosta hizasındaki yapısı bir bütün halinde olduğu için bloğun uygulanması ve blok oluşum süresi daha hızlıdır (11). Literatürde blok oluşma süresi supraklavikuler blokta 16-22 dk. olarak belirtilmiştir $(12,13)$. Gürkan ve ark. blok oluşumunda supraklavikuler bloğun infraklavikulere oranla istatiksel olarak anlamlı olmasa da 11,6 dk ile daha kisa sürede oluştuğunu bulmuşlardır (14). Bizim çalışmamızda bu oran 10,7 dk olarak literatürle uyumludur. Literatürde blok uygulama süresiyle ilgili sonuçlar supraklavikuler blok için 4-9 dk. arasındadır $(5,12,15)$. Bizim çalışmamızda da blok uygulama süresi ortalama $8,45 \mathrm{dk}$. olarak bulunmuştur. $\mathrm{Bu}$ sürelerin yine literatürle uyumlu olduğunu görmekteyiz. Buradaki blokla ilgili sürelerin farklı olmasındaki etkenler kullanılan lokal anestezik ilaç ve miktarı, lokal anestezik ilaca ilave edilen adjuvanlar ve uygulayıcının US deneyimi ile ilişkili olabilir. Kullanılan lokal anestezik miktarının blok başarısında etkili olduğu farklı dozlarla yapılmış çalışmalarda belirtilmiştir $(10,15)$. Çalışmamızda $40 \mathrm{ml}$. lokal anestezik ile başarılı sonuçlar elde ettiğimizi söyleyebiliriz, fakat lokal anestezik miktarını azaltmaya yönelik yeni çalışmaların olması da bu konuda bizlere yardımcı olacaktır.

Supraklavikuler blokta en ciddi komplikasyon pnömotoraks ve vasküler travma oluşmasıdır. Perlas ve ark. yaptıkları çalışmada 47 farklı anestezistin uyguladığ $\breve{1}_{\text {US }}$ eşliğinde uygulanan 510 supraklavikuler blokta hiç bir hastada pnömotoraks gelişmemiştir (7). Bizim çalışmamızda hastaların hiçbirinde intraoperatif ve erken postoperatif dönemde komplikasyon görülmemiştir. Tüm bunlar dikkate alındığında hastalarımızda supraklavikuler brakiyal pleksus bloğu güvenli bir anestezi sağlamıştır.

Sonuç olarak üst ekstremite cerrahisinde sıklıkla kullandığımız US eşliğindeki brakiyal pleksus bloklarının periferik arter kesilerinde de hızlı ve güvenli bir şekilde uygulanabileceği kanaatindeyiz.

\section{KAYNAKLAR}

1. Weaaves FA, Hood DB, Yelkin AE. Vasculer injuries of the extremities, In: Rutherford RB, ed. Vasculer surgery, Philadelphia: Sounders Company. 2000;862-72.

2. De Silya W, Ubayasiri R. Challenges in the management of the extremity vasculer injuries: A wortine experience from a tertiory centre in Sri Lanka. World J Emerg Surg. 2011;10:6-24

3. Valentin N, Lomholt B, Jensen JS, Hejgaard N, Kreiner S. Spinal or general anaesthesia for surgery of the fractured hip? A prospective study of mortality in 578 patients. Br J Anaesth 1986;58: 284-91.

4. Liu SS, Ngeow JE, Yadeau JT. Ultrasound-guided regional anesthesia and analgesia: a qualitative systematic review. Reg Anesth Pain Med. 2009; 34: 47-59.

5. Chan VW, Perlas A, Rawson R, Odukoya O. Ultrasound guided supraclavicular brachial plexus block. Anesth Analg. 2003; 97 : 1514-17 


\section{DOI: $10.16899 /$ ctd.57811}

6. Sandhu NS, Capan LM. Ultrasound-guided infraclavicular brachial plexus block. Br J Anaesth 2002;89(2):254-59.

7. Perlas A, Lobo G, Lo N, Brull R, Chan V W.S, Karkhanis R. Ultrasound-guided supraclavicular block: outcome of 510 consecutive cases. Reg Anesth Pain Med. 2009;34(2):171-76

8. Zetlaoui PJ, Labbe JP, Benhamou D. Ultrasound guidance for axillary plexus block does not prevent intravascular injection. Anesthesiology. 2008;108(4):761.

9. Loubert C, Williams SR, Helie F, Arcand G. Complication during ultrasound-guided regional block: accidental intravascular injection of local anesthetic. Anesthesiology. 2008;108(4):759-60

10. Li T, Ye XH, Nan Y,Shi T,Ye QG, Ma JF et al. Comparison of ultrasound and nerve stimulation techniques for brachial plexus block for regional hemodynamic changes of upper extremity. Zhonghua Yi Xue Za Zhi. 2013;93(3):187-90

\section{Ozgur et al.}

11. Franco CD, Vieira ZE. 1,001 subclavian perivascular brachial plexus blocks: success with a nerve stimulator. Reg Anesth Pain Med 2000;25(1):41-46.

12. Koscielniak-Nielsen ZJ, Frederiksen BS, Rasmussen H, Hesselbjerg L. A comparison of ultrasound-guided supraclavicular and infraclavicular blocks for upper extremity surgery. Acta Anaesthesiol Scand 2009;53(5):620-26.

13. Chan VW, Perlas A, Rawson R, Odukoya O. Ultrasound guided supraclavicular brachial plexus block. Anesth Analg 2003;97(5):1514-17.

14. Gürkan Y, Hoşten T, Tekin M, Acar S, Solak M,Toker K. Brakiyal pleksus bloğunda ultrason eşliğinde supraklavikuler ve infraklavikuler yaklaşımın karşılaştırılması. Ağrı. 2012;24(4):159-64

15. Arcand G, Williams SR, Chouinard P, Boudreault D, Harris P, Ruel M, et al. Ultrasound-guided infraclavicular versus supraclavicular block. Anesth Analg 2005;101(3):886-90. 